Canadian

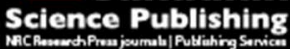

Applied Physiology, Nutrition, and Metabolism Physiologie appliquée, nutrition et métabolisme

\title{
Coronary Arterial BK Channel Dysfunction Exacerbates Ischemia Reperfusion-Induced Myocardial Injury in Diabetic Mice
}

\begin{tabular}{|r|l|}
\hline Journal: & Applied Physiology, Nutrition, and Metabolism \\
\hline Manuscript ID & apnm-2016-0048.R2 \\
\hline Manuscript Type: & Article \\
\hline Complete List of Authors: & $\begin{array}{l}\text { Lu, Tong; Mayo Clinic Minnesota, Cardiovascular Diseases } \\
\text { Jiang, Bin; the First Affiliated Hospital of Soochow University, Cardiology; } \\
\text { Mayo Clinic Minnesota, Cardiovascular Diseases } \\
\text { Wang, Xiao-Li; Mayo Clinic Minnesota, Cardiovascular Diseases } \\
\text { Lee, Hon-Chi; Mayo Clinic Minnesota, Cardiovascular Diseases }\end{array}$ \\
\hline Keyword: & $\begin{array}{l}\text { BK channel, angiotensin II type 1 receptor, vascular smooth muscle cell, } \\
\text { myocardial ischemia-reperfusion injury, diabetes }\end{array}$ \\
\hline \multicolumn{2}{|c}{} \\
\hline
\end{tabular}




\section{Coronary Arterial BK Channel Dysfunction Exacerbates Ischemia Reperfusion-Induced Myocardial Injury in Diabetic Mice}

Tong Lu, Bin Jiang, Xiao-Li Wang, Hon-Chi Lee

Corresponding Authors: Tong Lu, M.D., Ph.D., Department of Cardiovascular Diseases, Mayo Clinic, 200 First Street SW, Rochester, MN 55905, USA. Tel: 507-255-9653; Fax: 507-5386418; E-mail: lu.tong@mayo.edu

Bin Jiang, MD., PhD., Department of Cardiovascular Diseases, Mayo Clinic, 200 First Street SW, Rochester, MN 55905, USA. Department of Cardiology, the First Affiliated Hospital of Soochow University, 96 Shixin Street, Soochow, Jiangsu 215006, P. R. China. Email: szbjiang@yahoo.com

Xiao-Li Wang, MD., PhD., Department of Cardiovascular Diseases, Mayo Clinic, 200 First Street SW, Rochester, MN 55905, USA. Email: wang.xaioli@mayo.edu

Hon-Chi Lee, MD., PhD., Department of Cardiovascular Diseases, Mayo Clinic, 200 First Street SW, Rochester, MN 55905, USA. Email: lee.honchi@mayo.edu 


\begin{abstract}
The large conductance $\mathrm{Ca}^{2+}$-activated $\mathrm{K}^{+}(\mathrm{BK})$ channels, abundantly expressed in coronary artery smooth muscle cells (SMCs), play a pivotal role in regulating coronary circulation. A large body of evidence indicates that coronary arterial BK channel function is diminished in both type 1 and type 2 diabetes. However, the consequence of coronary BK channel dysfunction in diabetes is not clear. We hypothesized that impaired coronary BK channel function exacerbates myocardial ischemia reperfusion (I/R) injury in streptozotocin (STZ)-induced diabetic mice. Combining patch-clamp techniques and cellular biological approaches, we found that diabetes facilitated the colocalization of Angiotensin II (Ang II) type 1 receptors (AT1R) and BK channel $\alpha$-subunits (BK- $\alpha$ ), but not BK channel $\beta 1$-subunits (BK- $\beta 1)$, in the caveolae of coronary SMCs. Such caveolae compartmentalization in vascular SMCs not only enhanced Ang II-mediated inhibition in BK- $\alpha$, but also produced a physical disassociation between BK- $\alpha$ and BK- $\beta 1$, leading to increased infarct size in diabetic hearts. Most importantly, genetic ablation of caveolae integrity or pharmacological activation of coronary BK channels protected the cardiac function of diabetic mice from experimental $\mathrm{I} / \mathrm{R}$ injury in both in vivo and ex vivo preparations. Our results demonstrate a vascular ionic mechanism underlying the poor outcome of myocardial injury in diabetes. Hence, activation of coronary BK channels may serve as a therapeutic target for diabetic cardiovascular complications.
\end{abstract}

Key words: BK channel, angiotensin II type 1 receptor, vascular smooth muscle cell, myocardial ischemia-reperfusion injury, diabetes. 


\section{Introduction}

Diabetes mellitus has become an epidemic worldwide. The global prevalence of diabetes is estimated to be $9 \%$ among adults according to the World Health Organization global status report. Diabetes is associated with a 2- to 4-fold increase in the risks of cardiovascular diseases which remain the leading cause of death in both men and women with diabetes (Snell-Bergeon \& Wadwa, 2012). A large body of clinical evidence has shown that the poor prognosis of acute myocardial infarction and cardiac sudden death in patients diagnosed with diabetes is attributed to compromised coronary blood flow and increased susceptibility of myocardial ischemia (Kurisu et al., 2003; Cubbon et al., 2007; Yeung et al., 2012). Despite advances in the management of diabetes, the cardiovascular morbidity and mortality in diabetic patients remain twice that of non-diabetic patients (Wackers, 2005; Norhammar et al., 2007). However, the molecular mechanisms that underlie the poor cardiovascular outcome in diabetic patients are not fully understood.

Because of high unitary conductance and high density in coronary smooth muscle cells (SMCs), the large conductance $\mathrm{Ca}^{2+}$-activated $\mathrm{K}^{+}(\mathrm{BK})$ channels play a negative feedback role in the regulation of vascular tone and cardiac perfusion. Activation of vascular BK channels by elevated intracellular free $\mathrm{Ca}^{2+}$ concentrations gives rise to the generation of spontaneous transient outward currents that hyperpolarize the membrane potentials, shut off the voltagedependent $\mathrm{Ca}^{2+}$ channels in vascular SMCs and lead to vascular relaxation (Nelson et al., 1995; Jaggar et al., 1998). Functional vascular BK channels are octameric complexes with four poreforming $\alpha$ subunits (BK- $\alpha$, encoded by Slo1 gene) and four regulatory $\beta 1$ or $\gamma 1$ subunits (BK- $\beta 1$ or BK- $\gamma 1)$ (Tanaka et al., 1997; Evanson et al., 2014). In diabetes, however, the BK channel 
function is diminished in many vascular beds including those of coronary arteries (Lu et al., 2010; Zhang et al., 2010; Wang et al., 2012; Yi et al., 2014). Whether coronary BK channel dysfunction contributes to worsened outcome of cardiovascular diseases with diabetes has not been studied.

Caveolae are flask-shaped nonclathrin-coated plasma membrane structures that contain the signature protein, caveolin (Cav). Three Cav isoforms are known: Cav-1, Cav-2 and Cav-3. Cav1 and Cav-2 are present in vascular endothelial cells and SMCs, while Cav-3 is primarily expressed in cardiac and skeletal muscles (Krajewska \& Maslowska, 2004). The N-terminus of Cav-1 contains an important functional structure: the Cav scaffolding domain, which is essential for interaction with other proteins containing the Cav binding motifs (ФХФХXXXФ or $\Phi \mathrm{XXXXФХХХ,} \mathrm{where} \Phi$ represents an aromatic amino acid and $\mathrm{X}$ is any amino acid) (Krajewska \& Maslowska, 2004). Such Cav binding motifs are present in human BK- $\alpha$ (1102-


BK- $\gamma 1$. Caveolae are membrane microdomains that assemble signaling molecules including those of Ang II (Ushio-Fukai \& Alexander, 2006). Two types of Ang II receptors are expressed in the heart: type 1 (AT1R) and type 2 (AT2R) with AT1R being the dominant isoform that mediates the major cardiovascular effects of Ang II (Dasgupta \& Zhang, 2011). We have demonstrated that Ang II promoted in AT1R trafficking into the caveolae of vascular SMCs, forming the BK channel-AT1R-caveolae microdomain complexes. Importantly, such caveolae compartmentation was enriched in diabetic vessels, potentiating the inhibitory effect of Ang II on BK channels in the vicinity and promoting coronary vasoconstriction (Lu et al., 2010). In addition, it has been reported that caveolae facilitated direct coupling between BK channels and 
L-type $\mathrm{Ca}^{2+}$ channels in vascular SMCs to regulate vascular tone (Suzuki et al., 2013). However, the role of BK channel-AT1R-caveolae microdomain complexes in cardiovascular diseases, particularly with diabetes, has not been established. In this study, we found that dysregulation of coronary smooth muscle BK channel activity contributes to exacerbated ischemia/reperfusion (I/R) injury in diabetic mouse hearts, due to an increase of BK chanel-AT1R-caveolae microdomain compartmentation in coronary SMCs. Activation of coronary BK channels and suppression of AT1R-caveolae signaling minimized myocardial I/R injury in diabetic mice. Hence, protection of coronary BK channel function may serve as a novel molecular target for the treatment of cardiovascular complications in diabetes.

\section{Materials and methods}

Diabetic mouse model - Male Cav-1 null mice $\left(\mathrm{Cav}-1^{-/-}, \mathrm{Cav1}^{\mathrm{tm} 1 \mathrm{M} 1 \mathrm{~s}} / \mathrm{J}\right)$ and wild type (wt) control mice (C57BL/6J) were purchased from the Jackson Laboratory at 4 weeks of age. Mice received a STZ injection (100 mg/kg body weight, ip.) and those with blood glucose higher than $300 \mathrm{mg} / \mathrm{dl}$ were considered diabetic. Eight weeks after developing hyperglycemia, mice and agematched controls were sacrificed and used for experiments. All animal protocols were approved by the Mayo Clinic Institute Animal Care and Use Committee (Rochester, MN).

Coronary SMC isolation and BK channel current recording - Mouse coronary SMCs were enzymatically isolated for whole-cell $\mathrm{K}^{+}$current recordings as we have previously described (Lu et al., 2010; Lu et al., 2012). The pipette solution contained (in $\mathrm{mM}$ ): $\mathrm{KCl} 140, \mathrm{MgCl}_{2}$ 0.5, $\mathrm{Na}_{2} \mathrm{ATP} 5.0, \mathrm{Na}_{2} \mathrm{GTP} 0.5$, HEPES 10.0, EGTA $1.0, \mathrm{CaCl}_{2} 0.465\left(\sim 0.2 \mu \mathrm{M}\right.$ free $\left.\mathrm{Ca}^{2+}\right)$ and $\mathrm{pH}$ at 7.38. The bath solution contained (in $\mathrm{mM}$ ): $\mathrm{NaCl} 145, \mathrm{KCl} 5.6, \mathrm{MgCl}_{2}$ 1.0, $\mathrm{CaCl}_{2}$ 1.0, $\mathrm{HEPES}$ 10.0, glucose 5.0 and $\mathrm{pH}$ at 7.40. BK currents were defined by its sensitivity to $0.1 \mu \mathrm{M}$ 
iberiotoxin (IBTX, a membrane impermeable BK channel-specific blocker) and were obtained by subtraction of the IBTX-insensitive component from the total $\mathrm{K}^{+}$currents. All patch clamp experiments were conducted at room temperature $\left(22^{\circ} \mathrm{C}\right)$.

Sucrose gradient density centrifugation — The cellular distributions of caveolae-targeted BK channels and AT1R in mouse aortic SMCs were determined by sucrose density gradient fractionation as previously described (Wang et al., 2005; Lu et al., 2010). Cells were homogenized in $500 \mathrm{mM} \mathrm{Na} \mathrm{CO}_{3}$ with $2 \%$ protease inhibitors (v/v), and then centrifuged at $5,000 \mathrm{rpm}$ at $4{ }^{\circ} \mathrm{C}$ for $10 \mathrm{~min}$. One $\mathrm{ml}$ of the supernatant were adjusted to $40 \%$ sucrose-MBS (2[N-morpholino]-ethanes $\mu$ fonic acid) by adding $1 \mathrm{ml}$ of $80 \%$ sucrose-MBS, placed to the bottom of a 6-ml ultracentrifuge tube, layered with a 2-ml discontinuous sucrose gradient (40\%, 30\% and $5 \%$, and centrifuged at $32,000 \mathrm{rpm}$ at $4{ }^{\circ} \mathrm{C}$ for $20 \mathrm{~h}$. Eight fractions of $1.25 \mathrm{ml}$ each were collected and analyzed by immunoblotting.

Co-immunoprecipitation (Co-IP) and immunoblotting - Co-IP and immunoblotting were performed as we have previously reported (Lu et al., 2010; Lu et al., 2012). Mouse aortas were

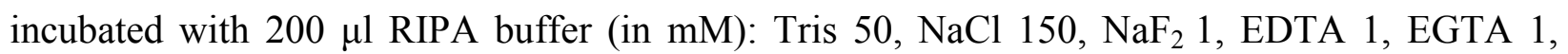
$\mathrm{NaVO}_{4} 1$, and $1 \%$ Triton $\mathrm{X}-100(\mathrm{pH} \mathrm{7.5})$ and $1 \mu \mathrm{l}$ protease inhibitor on ice for $30 \mathrm{~min}$, homogenized and then centrifuged at $2000 \mathrm{rpm}$ at $4{ }^{\circ} \mathrm{C}$ for $10 \mathrm{~min}$. The supernatant $(200 \mu \mathrm{g}$ protein in $200 \mu \mathrm{l}$ ) was incubated with $4 \mu \mathrm{g}$ anti-Cav-1 antibody (Santa Cruz Biotechnology, Inc., catalog number: sc-7875) at $4{ }^{\circ} \mathrm{C}$ overnight. Incubation with same amount of $\operatorname{IgG}$ severed as a negative control. The samples were then incubated with $20 \mu$ Protein G Plus-Agarose (Santa Cruz Biotechnology, Inc.) at $4{ }^{\circ} \mathrm{C}$ for $2 \mathrm{~h}$. After centrifugation at $1000 \mathrm{rpm}$ for $7 \mathrm{~min}$ and washed twice with RIPA/protease inhibitor buffer, the immunoprecipitates were collected and eluted 
from Agarose with $30 \mu \mathrm{l}$ SDS-PAGE loading buffer per tube, resolved by polyacrylamide gel electrophoresis and blotted against rabbit anti-BK- $\alpha$ antibodies (1:200, custom made) and rabbit anti-AT1R antibody (1:200, Santa Cruz Biotechnology, Inc., catalog number sc-1173). Custommade rabbit polyclonal anti-BK- $\alpha$ and anti-BK- $\beta 1$ antibodies against rat BK $\alpha$-subunit peptide (KTKEAQKINNGSSQADGTLKPVDE) and rat BK- $\beta 1$ peptide (HTEDTRDQNQQCSYIPRNL) were made in Mayo Clinic Antibody Core Facility as we have previously published (Wang et al., 2005;Lu et al., 2010;Zhang et al., 2010;Yi et al., 2014). Optical density of the bands was analyzed using Scion Image software (Scion Corp.).

Confocal immunofluorescence microscopy — Freshly isolated mouse coronary SMCs were fixed with $4 \%$ formaldehyde on glass slides for 30 min and permeated with $0.1 \%$ Triton X-100 in PBS for 2 min. After incubation with 10\% normal goat serum in PBS for $1 \mathrm{~h}$, cells were incubated with monoclonal anti-Cav-1 antibody (1:200) plus either polyclonal anti-BK- $\alpha$ (1:100) or antiAT1R (1:100) antibodies. Cells were washed with PBS and the fluorescein isothiocyanateconjugated goat anti-mouse secondary antibody (1:1000) or Texas Red-conjugated goat-antirabbit secondary antibody (1:500) was applied for $1 \mathrm{~h}$. After washing with PBS, a coverslip was applied to the glass slide with a drop of ProLong Gold antifade reagent (Molecular ProbesInvitrogen Co., catalog number 36934). Cells were visualized using a confocal laser microscope (LSM 510, Zeiss) with a 60X water immersion lens (Wang et al., 2005; Lu et al., 2010). Quantitative correlation of the fluorescence intensities of two images was analyzed using ImageJ JaCop (Bolte \& Cordelieres, 2006; Schneider et al., 2012).

HEK293 cell line stalely expressing hSlo gene and site-directed mutagenesis - $1 \mu \mathrm{g}$ hSlo cDNA/pTracer-CMV2 (accession no. NM_001014797) was transfected into HEK293 cells using 
Effectene Transfection Reagent kit (Qiagen Co.). After 48-h transfection, the cells expressing hSlo gene at high levels were selected by growth in 10\% FBS culture medium (Gibco-Invitrogen Ltd.) containing $1.0 \mathrm{mg} / \mathrm{ml}$ Geneticin (Gibco-Thermo Fisher Scientific Inc.) for four weeks. Only the transfected cells (hSlo-HEK293 cell line) with resistance to Geneticin survived in long-term cultures. Human EGFP-tagged Cav-1 cDNA/pcDNA3.1 (accession no. NM_001753) was transiently co-transfected with human AT1R cDNA/pcDNA3.1 (accession no. NM_000685) in the hSlo-HEK293 cells. The transfected cells were detected by the presence of strong green fluorescent protein under ultraviolet microscopy (IX70, Olympus) $48 \mathrm{~h}$ after transfection. The AT1R F309A mutation was generated by PCR (forward: 5'GGCTTTCTGGGGAAAAAAGCTAAAAGATATTTTCTCCAGC-3'; $\quad$ reward: 5'GCTGGAGAAAATATCTTTTAGCTTTTTTCCCCAGAAAGCC-3') according to the manufacture's protocol of the QuickChange site-directed mutagenesis kit (Stratagene, Inc.). The construct orientation and correctness of the mutation were verified by DNA sequencing (DNA Facility Core of Mayo Clinic, Rochester, MN).

Ex vivo myocardial I/R studies — Isolated mouse hearts were rapidly mounted on the cannulus of a modified Langendorff apparatus and perfused with Tyrode's solution (in mM): $\mathrm{NaCl} 119$, $\mathrm{KCl} 4.8, \mathrm{KH}_{2} \mathrm{PO}_{4}$ 1.2, $\mathrm{MgSO}_{4}$ 1.2, $\mathrm{CaCl}_{2}$ 1.0, $\mathrm{NaHCO}_{3}$ 24.9, glucose 10.0, pyruvate 5.0, heparin $1200 \mathrm{U} / \mathrm{L}, \mathrm{pH}=7.4$ ), equilibrated with $95 \% \mathrm{O}_{2}-5 \% \mathrm{CO}_{2}$, using a peristaltic pump (P720, Instech Laboratories Inc.) at $3.0 \mathrm{~mL} / \mathrm{min}$ at $37^{\circ} \mathrm{C}$. The left atrium was cut open, and a balloon catheter was inserted through the mitral valve into the left ventricular chamber. The balloon catheter was connected to a pressure transducer (Gould Inc.) for monitoring left ventricular pressure. A bipolar electrode was placed on the ventricular epicardium for pacing (350 beats/min) and for 
monitoring heart rate. Hearts were paced at 350 beats/min throughout all experiments. The left ventricular developed pressure (LVDP) was calculated as the left ventricular systolic pressure minus the left ventricular diastolic pressure before the onset of experimental ischemia and at the end of reperfusion as previously described (Gelpi et al., 2002). The ischemia-reperfusion protocols (Gelpi et al., 2002) for isolated hearts were conducted as follows: (i) Control group: 30 min of normal perfusion with Tyrode's solution, then $40 \mathrm{~min}$ of global ischemia (no flow), followed by 60 min of reperfusion with Tyrode's solution; (ii) Ang II group: 30 min of perfusion with $2 \mu \mathrm{M}$ Ang II, then $40 \mathrm{~min}$ of global ischemia, followed by 60 min of perfusion with $2 \mu \mathrm{M}$ Ang II; (iii) Ang II+Losartan (an AT1R specific blocker) group: 30 min of perfusion with $2 \mu \mathrm{M}$ Ang II and $10 \mu \mathrm{M}$ Losartan, then 40 min of global ischemia, followed by 60 min of perfusion with $2 \mu \mathrm{M}$ Ang II and $10 \mu \mathrm{M}$ Losartan; (iv) Ang II+NS1619 (a BK channel activator) group: 30 min of perfusion with $2 \mu \mathrm{M}$ Ang II and $10 \mu \mathrm{M}$ NS1619, then 40 min of global ischemia, followed by 60 min of perfusion with $2 \mu \mathrm{M}$ Ang II and $10 \mu \mathrm{M}$ NS1619; (v) IBTX (a membrane impermeable BK channel-specific blocker) group: 30 min of perfusion with $0.2 \mu \mathrm{M}$ IBTX, then $40 \mathrm{~min}$ of global ischemia, followed by $60 \mathrm{~min}$ of perfusion with $0.2 \mu \mathrm{M}$ IBTX; (vi) IBTX+NS1619: $30 \mathrm{~min}$ of perfusion with $0.2 \mu \mathrm{M}$ IBTX and $10 \mu \mathrm{M}$ NS1619, then 40 min of global ischemia, followed by 60 min of perfusion with $0.2 \mu \mathrm{M}$ IBTX and $10 \mu \mathrm{M}$ NS1619.

At the end of the I/R procedure, the heart was perfused with 1\% 2,3,5-triphenyltetrazolium chloride (TTC) in $0.1 \mathrm{M}$ phosphate buffer (pH 7.4) at $37^{\circ} \mathrm{C}$ for $10 \mathrm{~min}$ (Gao et al., 2002). Viable myocardium containing dehydrogenase enzymes was stained brick red by reacting with TTC, whereas infarct tissue remained unstained (white color) because of the lack of the enzymes. After 
incubation overnight with $10 \%$ formaldehyde, the heart was cut into 6 to 8 slices (each $0.1 \mathrm{~mm}$ thick) and the infarct weight was calculated as:

$\mathrm{A} 1 \mathrm{~W} 1+\mathrm{A} 2 \mathrm{~W} 2+\cdots \cdots+\mathrm{A} 7 \mathrm{~W} 7+\mathrm{A} 8 \mathrm{~W} 8$, where $\mathrm{A}$ is the area of infarct as a percentage of the total area of the slice and $\mathrm{W}$ is the weight of the respective section. TTC-stained area and TTC negative area were measured digitally using ImageJ software (Schneider et al., 2012). The cardiac infarct size $(\Sigma \mathrm{AW})$ was presented as a percentage of the total weight of the heart.

In vivo myocardial $I / R$ studies — The surgical in vivo ischemia-reperfusion procedure was performed as previously described (Suzuki et al., 2002). Mice were anesthetized with pentobarbital (60 mg/kg, ip.) and anesthesia was maintained by $1.5 \%$ isoflurane with $\mathrm{O}_{2}$ through a vaporizer (Midmark Co.). Anesthetized mice were placed on a heating plate $\left(\right.$ at $\left.37^{\circ} \mathrm{C}\right)$ to keep the body temperature stable. Mice were tracheotomized, intubated, and ventilated with a small animal ventilator (Kent Scientific Co.). The tidal volume and ventilation rate were 0.5 to $0.6 \mathrm{ml}$ and 100 to 120 strokes per min, respectively. Thoracotomy was performed through the third left intercostal space, and the pericardium was opened. A 7-0 silk suture was passed around the left anterior descending coronary artery (LAD) using a tapered needle. Electrocardiogram (ECG) limb leads were placed on the fore- and hind-limbs to record cardiac ECG throughout the experiment. A balloon catheter was inserted into the femoral artery to monitor systemic blood pressure. Acute myocardial ischemia was induced by ligation of the LAD for 40 min, followed by a 60 -min of reperfusion achieved by releasing the ligation. After reperfusion, the heart was rapidly excised and mounted on the cannulus connected to a syringe. $1 \% \mathrm{TTC}\left(10 \mathrm{ml}\right.$, at $\left.37{ }^{\circ} \mathrm{C}\right)$ was injected into the coronaries retrogradely through the aorta. Then, the heart was cut into 6 to 8 transverse slices for infarct size measurements. 
Statistical analysis — Data were presented as mean \pm S.E.M. Statistical analysis was performed using SigmaStat 3.5 software (Systat Software, Inc.). One way ANOVA followed by Tukey's test was employed to compare data from multiple groups. Student's $t$ test was used to compare data between two groups. Paired $t$ test was used to compare data from same subjects before and after treatment. Statistical significance was defined as $\mathrm{p}<0.05$.

\section{Results}

Myocardial I/R injury studies in vivo — In vivo myocardial I/R injury was accomplished by a 40min period of LAD ligation followed by a 60-min period of reperfusion (Fig. 1A). Myocardial infarct size was $20.2 \pm 2.7 \%(n=5)$ in control wt mice but $42.2 \pm 5.6 \%$ in diabetic wt mice $(n=5$, $\mathrm{p}=0.007$ vs controls). However, the infarct size was $24.9 \pm 4.6 \%$ in non-diabetic $\mathrm{Cav}-1^{-/-}$mice $\left(n=5, p=N . S\right.$. vs non-diabetic wt mice) and was $27.0 \pm 1.5 \%$ in diabetic Cav- $1^{-/-}$mice $(n=5, p=0.69$ vs non-diabetic Cav-1 ${ }^{-/}$mice) (Fig. 1B). There was 55.3\% reduction in diabetic effects on I/Rinduced cardiac infarct size in $\mathrm{Cav}-1^{-/-}$mice. Hence, the absence of caveolae integrity reduced the myocardial injury and infarct size produced by $\mathrm{I} / \mathrm{R}$ in diabetic mice to the level of non-diabetic mice.

Myocardial I/R injury studies ex vivo — To determine the role of coronary BK channel function on $\mathrm{I} / \mathrm{R}$-induced myocardial infarction, we performed ex vivo myocardial $\mathrm{I} / \mathrm{R}$ injury studies in Langendorff-perfused mouse hearts subjected to $30 \mathrm{~min}$ of pretreatment with saline (control) or chemicals (Ang II, IBTX or NS1619), followed by 40 min of global ischemia and 60 min of reperfusion with saline or chemicals. In non-diabetic wt mouse hearts, infarct size was $44.1 \pm 2.3 \%(n=8)$ under control conditions but increased to $80.6 \pm 4.3 \%(n=7)$ after pretreatment with $2 \mu \mathrm{M}$ Ang II ( $\mathrm{p}=5.1 \times 10^{-6}$ vs non-diabetic controls). The effect of Ang II on myocardial 
infarct size was antagonized by $10 \mu \mathrm{M}$ Losartan $\left(49.0 \pm 4.6 \%, \mathrm{n}=8, \mathrm{p}=2.4 \times 10^{-4}\right.$ vs Ang II and $\mathrm{p}=0.35$ vs non-diabetic controls) and by $10 \mu \mathrm{M} \operatorname{NS} 1619(49.0 \pm 7.1 \%, \mathrm{n}=7, \mathrm{p}=0.002$ vs Ang II; $\mathrm{p}=0.47$ vs non-diabetic controls). Pretreatment with $0.2 \mu \mathrm{M}$ IBTX also increased the I/R-induced infarct size $(72.5 \pm 7.6 \%, n=7, p=0.003$ vs non-diabetic controls), but the effect of IBTX was not salvaged by the presence of $10 \mu \mathrm{M} \operatorname{NS} 1619(69.4 \pm 1.8 \%, \mathrm{n}=7, \mathrm{p}=0.72$ vs IBTX treatment) (Fig. 2). These results indicate that sarcolemmal BK channels of coronary SMCs are critically involved in I/R-induced myocardial injury since the protective effect of NS1619 was abolished by the membrane-impermeable IBTX. In addition, diabetic wt mice had a myocardial infarct size $\left(90.7 \pm 4.0 \%, \mathrm{n}=9, \mathrm{p}=1.3 \times 10^{-3}\right.$ vs non-diabetic controls) as large as those of non-diabetic wt mice with Ang II or IBTX pretreatment ( $p=0.28$ vs Ang II treatment; $p=0.81$ vs IBTX treatment). Strikingly, pretreatment with $10 \mu \mathrm{M}$ NS1619 dramatically reduced I/R-induced infarct size $\left(27.7 \pm 2.3 \%, \mathrm{n}=8, \mathrm{p}=3.1 \times 10^{-6}\right.$ vs diabetes $)$ in wt diabetic mouse hearts, to a level even smaller than those of non-diabetic control mice $\left(\mathrm{p}=1.4 \times 10^{-4}\right)$ (Fig. 2), suggesting that the NS1619 effects on cardiac infarct size is more complicated than our original thoughts.

In non-diabetic Cav- ${ }^{-/-}$mouse hearts, the infarct size $(28.8 \pm 2.4 \%, \mathrm{n}=7)$ induced by $\mathrm{I} / \mathrm{R}$ procedure was about half that of non-diabetic wt controls $\left(p=5.6 \times 10^{-4}\right)$. Pretreatment and reperfusion with $2 \mu \mathrm{M}$ Ang II produced significantly larger infarcts $(46.7 \pm 3.6 \%, \mathrm{n}=7, \mathrm{p}=0.003 \mathrm{vs}$ non-diabetic Cav-1 $1^{-/}$controls), similar to those of non-diabetic wt mice without treatment. IBTX pretreatment also greatly augmented the infarct size $\left(84.9 \pm 3.9 \%, n=7, p=2.2 \times 10^{-7}\right.$ vs non-diabetic $\mathrm{Cav}_{-1} 1^{-/-}$controls), which was twice that of Ang II-treated Cav-1 $1^{-/-}$mice $\left(\mathrm{p}=1.0 \times 10^{-4}\right)$ and comparable to that of non-diabetic wt with IBTX treatment $(p=0.23)$ (Fig. 3). It is worth noting that the effect of IBTX on I/R-induced myocardial infarction was independent of Cav-1 
expression in coronary SMCs, suggesting that AT1R-caveolae signaling is the upstream of coronary BK channel modulation. Furthermore, the presence of diabetes significantly enlarged $\mathrm{I} / \mathrm{R}$-induced myocardial infarct size in $\mathrm{Cav}^{-1} \mathrm{1}^{-/}$mice $(44.7 \pm 6.0 \%, \mathrm{n}=9, \mathrm{p}=0.040$ vs non-diabetic Cav- $1^{-/-}$controls $)$, but it was smaller than that of diabetic wt mice $\left(p=5.8 \times 10^{-4}\right)$ and IBTX-treated non-diabetic Cav-1 ${ }^{-/-}$mice $\left(\mathrm{p}=2.9 \times 10^{-4}\right)$ (Fig. 3). In addition, pretreatment with $10 \mu \mathrm{M}$ NS1619 significantly minimized myocardial infarct size in diabetic Cav-1 ${ }^{-/-}$mice to $23.6 \pm 5.4 \%(n=7$, $\mathrm{p}=0.023 \mathrm{vs}$ diabetic Cav- $1^{-/-}$mice), similar to that of non-diabetic Cav- $1^{-/-}$mice without treatment (Fig. 3). The changes in LVDP of wt and $\mathrm{Cav}-1^{-/-}$mice before and after $\mathrm{I} / \mathrm{R}$ procedure are summarized in Table 1.

Colocalization of BK- $\alpha$ and AT1R in the caveolae of coronary SMCs of mice - We determined the cellular distribution of BK- $\alpha, \mathrm{BK}-\beta 1$ and AT1R in cultured mouse coronary SMCs by sucrose density gradient and immunoblot analysis. As shown in Fig. 4A, BK- $\alpha$ and AT1R proteins were abundantly found in the low buoyant density, caveolae-rich membrane fractions (No. 2 to 4 ) and in whole cell lysates, while BK- $\beta 1$ protein expressions in those caveolae-rich membrane fractions were very little, compared to those in the cell lysate and the heavy density fractions (No. 7 to 8). Confocal immunofluorescence imaging of freshly isolated mouse coronary SMCs also showed that the signals of BK- $\alpha$ with Cav-1, and BK- $\alpha$ with AT1R were overlapped (Fig. 4B). Pixel-wise correlation between the staining intensities of two images was estimated using the ImageJ JaCop software, with the slope (Pearson correlation coefficient, $\gamma$ ) of 0.77 between BK- $\alpha$ with Cav-1 signals, and 0.82 between BK- $\alpha$ with AT1R signals respectively. Note: $\gamma$ is from 1 to -1 , with 1 standing for complete positive correlation and -1 for negative 
correlation, with 0 standing for no correlation). In addition, co-IP studies detected both BK- $\alpha$ and AT1R in the immunoprecipitates pulled down by anti-Cav-1 antibody from the cell lysates of mouse aortas, suggesting there was physical interaction of Cav-1, BK- $\alpha$ and AT1R. Moreover, the colocalization of $\mathrm{BK}-\alpha$ and $\mathrm{AT} 1 \mathrm{R}$ in caveolae microdomain complexes was enriched in diabetic mouse vessels, compared to that of non-diabetic controls (Fig. 4C).

Cav binding motif of AT1R is essential for Ang II-mediated BK channel inhibition — We have reported that pretreatment of Ang II facilitated AT1R trafficking into the caveolae of aortic SMCs of rats and enhance its effect on BK channel inhibition, and ablation of Cav-1 preserved BK channel activity in diabetic vessels ( $\mathrm{Lu}$ et al., 2010). To further delineate the molecular mechanism underlying BK channel dysregulation by caveolae-targeting, we generated an AT1R mutation in the Cav binding motif by substituting the phenylalanine residue at 309 with an alanine (AT1R F309A) and examined the effects of Ang II on hSlo-HEK293 cell line $48 \mathrm{~h}$ after co-transfection of Cav-1 wt cDNAs with AT1R wt or the AT1R F309A mutant. Fig. 5A shows the time course of hSlo currents recorded at $+100 \mathrm{mV}$ in hSlo-HEK293 cell line transiently cotransfected with Cav-1 wt and AT1R wt cDNAs after exposure to Ang II (2 $\mu \mathrm{M})$, Losartan (10 $\mu \mathrm{M})$ and IBTX $(0.1 \mu \mathrm{M})$. Ang II suppressed about $40 \%$ of hSlo currents and the Ang II effect was reversible upon washing out and blocked by Losartan (Fig. 5B). Ang II had no effect on hSlo currents stably expressed in HEK293 cells after co-transfection with AT1R F309A and Cav-1 wt cDNAs, while BK channel expression remained intact as shown by sensitivity to IBTX (Fig. 6A). Fig. 6B shows whole-cell hSlo currents tracings and the current-voltage relationships (I-V curve) at baseline and after exposure to $2 \mu \mathrm{M}$ Ang II. A critical substitution in the Cav binding motif in AT1R completely abolished the inhibitory effect of Ang II on hSlo, revealing 
the functional consequences of physical interaction between AT1R and Cav-1. Our results demonstrate that caveolae in vascular SMCs is a central platform for Ang II biological effects on BK channel regulation.

\section{Discussion}

The clinical outcome of patients with acute coronary events is dependent on the maintenance of effective myocardial perfusion (Wackers, 2005; Esposito et al., 2014). Studies over the last couple of decades improved our understanding on the pathological mechanisms of myocardial $\mathrm{I} / \mathrm{R}$ injury which involve myocardial factors and vascular factors (Yellon \& Hausenloy, 2007). The vascular factors are attributed to microvessel obstruction and blood flow deficiency in previously ischemic region of the heart after coronary angioplasty, contributing to the "noreflow" phenomenon (Hoffmann et al., 2003). It is well known that pathological and functional changes in diabetic coronary endothelium contribute to exacerbated I/R-induced myocardial injury, including increased platelet activation and clot coagulation, as well as aggravated inflammatory response (Hausenloy \& Yellon, 2013). In this study, we have further demonstrated that coronary smooth muscle BK channel activity is also important for the I/R-induced myocardial infarction, particularly in diabetic hearts. Activation of AT1R by Ang II and suppression of BK channels by IBTX enlarged myocardial infarct size in non-diabetic mice, similar to the effects of diabetes. Blockade of AT1R by Losartan and activation of BK channel by NS1619 reduced Ang II-induced myocardial infarct size and improved cardiac contractility. More importantly, the infarct size in diabetic hearts was reduced by NS1619 to a level even smaller than that in diabetic controls and in Ang II-treated mice, suggesting coronary BK channel dysfunction may play a fundamental role in the outcome of myocardial I/R injury, particularly in diabetes. It has been reported that NS1619 protects the heart by activating 
myocardial mitochondrial BK channels (Singh et al., 2013), cardiac neuron BK channels (Wojtovich et al., 2013) and other non-selective ion channels (Cancherini et al., 2007). Indeed, activation of mitochondrial BK channels has protective effects on cardiac I/R injury (Sakamoto et al., 2008; Borchert et al., 2011; Singh et al., 2013; Testai et al., 2013). We believe that activation of sarcolemma BK channels in coronary SMCs is also critical in reducing I/R-induced myocardial infarct size in diabetic mice, based on following reasons: First, the effects of NS1619 on cardiac protection were abolished by IBTX which is membrane impermeable, indicating the involvement of sarcolemmal BK channels rather than mitochondrial BK channels. It is worth noting that BK channels are not found in the sarcolemma of cardiac myocytes (Singh et al., 2012) and are poorly expressed in the most freshly isolated vascular endothelial cells (Feletou, 2009). Second, significant reduction in myocardial infarct size was associated with ablation of the Cav-1 gene that is expressed in the vasculature, but not in myocardium which expresses Cav3. A recent study also showed that forskolin-induced myocardial infarct size reduction was blocked by IBTX, demonstrating the protective role of vascular BK channels in whole heart I/R injury (Heinen et al., 2014).

The molecular mechanisms underlying BK channel regulation by caveolae-targeting could be complicated. It has been reported that inhibition of BK channel activity by Ang II is mediated through posttranslational modification of BK- $\alpha$ protein ( $\mathrm{Lu}$ et al., 2010) or a direct interaction between AT1R and BK- $\alpha$ proteins (Zhang et al., 2014). In addition, binding of BK- $\alpha$ to Cav scaffolding domain results in a decrease of BK channel current density in cultured endothelial cells (Wang et al., 2005; Riddle et al., 2011). Interestingly, we found that there is an increase of colocalization of BK- $\alpha$ and AT1R, but not BK- $\beta 1$, in the caveolae of diabetic vascular SMCs. 
Such cellular distribution of protein profiles will greatly suppress BK- $\alpha$ activity not only through proximity with AT1R and its downstream signaling, but also through a physical dissociation with BK- $\beta 1$. This contention is supported by the finding that with the loss of caveolae integrity, coronary BK channel activity is preserved and I/R-induced myocardial infarct size in diabetic mice is attenuated.

Ang II plays an essential role in the regulation of cardiovascular homeostasis. AT1R and its associated signaling proteins, such as G-proteins, non-phagocytic NAD(P)H oxidases (NOXs) and c-Src kinase, are colocalized in the caveolae of vascular SMCs (Ushio-Fukai \& Alexander, 2006; Lu et al., 2010). Upon stimulation by Ang II, AT1R translocates into the caveolae, activates protein kinase $\mathrm{C}$ and NOXs, promotes reactive oxygen species (ROS) generation (Touyz \& Schiffrin, 2000) and leads to the redox-mediated protein modification of BK channels (Lu et al., 2010). It is known that development of diabetic vascular dysfunction is associated with augmented Ang II signaling and increased ROS production (Van Linthout et al., 2008; Giacco \& Brownlee, 2010). However, the roles of the renin-angiotensin system in cardiac $\mathrm{I} / \mathrm{R}$ injury remain controversial. Autoradiography and immunohistochemistry experiments found that AT1R expression in the infarct area of rats was upregulated after myocardial I/R (Higuchi et al., 2010). AT1R antagonists preserved cardiac function against I/R injury (Flynn \& Akers, 2003; Han et al., 2013). In contrast, some studies suggested that Ang II had protective effects on cardiac I/R injury through Ang II initiated myocardial preconditioning as a result of increase in mitochondrial ROS generation with activation of JNK and p38 MAP kinase pathways (Kimura et al., 2005; Das et al., 2006). Reasons for the discrepancy among these studies are unclear, but they may reflect the differences in the animal species used and experimental conditions employed. In particular, the range of Ang II concentration for vasoconstriction studies was 
varied from $10^{-12}$ to $10^{-4} \mathrm{M}$ and the efficiency of Ang II was vascular bed dependent (Pallone, 1994; Batenburg et al., 2004; Patzak et al., 2005; Park et al., 2012). Since there was a 10-fold increase of Ang II production in cardiomyocytes of STZ-induced diabetic rats (Singh et al., 2008), we applied Ang II in $10^{-6} \mathrm{M}$ range to Langendorff-perfused hearts to mimic a gain of activity of renin-angiotensin in diabetic hearts as we have published (Lu et al., 2010). We found that the worsening of I/R-induced myocardial injury by Ang II was caveolae-dependent and mediated through the inhibition of coronary BK channel function. In Cav- $1^{-/}$hearts, the I/Rinduced myocardial infarct size produced by Ang II was about 40\% smaller than that in wt mice, suggesting the role of caveolae in mediating the detrimental effects of Ang II. However, the effect of IBTX on I/R-induced myocardial infraction was similar between $\mathrm{Cav}-1^{-/-}$and wt mice, indicating that coronary BK channels are the downstream of AT1R signaling.

Our study has potential limitations. First, cardiovascular complications are commonly associated with type 2 diabetes mellitus. However, STZ injection usually induces type 1 diabetes rather than type 2 diabetes. Use of high fat-diet or genetic induced type 2 diabetic mouse models will have a better clinical relevant. Second, the maximal efficacy of Ang II is about in $10^{-7} \sim 10^{-8}$ $\mathrm{M}$ range. We applied a relative high Ang II concentration to isolated perfusion hearts to mimic an increase of Ang II production in diabetes, although we did not measure serum Ang II level in STZ diabetic mice. However, we have shown deleterious roles of caveolae and diabetes in myocardial I/R study in vivo, similar to the results observed from ex vivo study. Hence, we believe that conclusions derived from these experiments are valid.

In summary, our study demonstrated a novel mechanism by which the receptor-channelcaveolae microdomain complexes in coronary SMCs suppressed BK channel function and exacerbated myocardial infarction in diabetic mice. Protection and activation of coronary BK 
channel function may provide a new strategy in the prevention and the treatment of cardiovascular complications in diabetes.

Conflict of interest: The authors declare that they have no conflict of interests in the contents of this article.

\section{Acknowledgement}

This work was supported by grants from the American Diabetes Association (1-12-BS-119 and 1-16-IBS-195), and from the National Institutes of Health (HL-74180 and HL-080118).

Author contributions: T. L. deigned research, performed research, analyzed data and wrote paper; B. J. and X-L.W. performed experiments and analyzed results. H-C.L. discussed and prepared the manuscript.

Footnotes: Ang II, Angiotensin II; $\mathrm{AT}_{1} \mathrm{R}$, Ang II type 1 receptor; $\mathrm{BK}$ channel, the large conductance $\mathrm{Ca}^{2+}$-activated $\mathrm{K}^{+}$channel; BK- $\alpha$, BK channel $\alpha$ subunit; Cav, Caveolin; Co-IP, coimmunoprecipitation; ECG, Electrocardiogram; IBTX, iberiotoxin; IPs, immunoprecipitates; I/R, ischemia/reperfusion; SMC, smooth muscle cell; STZ, streptozotocin; TTC, 2,3,5triphenyltetrazolium chloride; wt, wild type. 


\section{References}

Batenburg, W.W., Garrelds, I.M., Bernasconi, C.C., Juillerat-Jeanneret, L., van Kats, J.P., Saxena, P.R., et al. 2004. Angiotensin II type 2 receptor-mediated vasodilation in human coronary microarteries. Circulation 109: 2296-2301. PMID:15117835

Bolte, S., and Cordelieres, F.P. 2006. A guided tour into subcellular colocalization analysis in light microscopy. J. Microsc. 224: 213-232. PMID:17210054

Borchert, G.H., Yang, C., and Kolar, F. 2011. Mitochondrial BKCa channels contribute to protection of cardiomyocytes isolated from chronically hypoxic rats. Am. J. Physiol. 300: H507513. PMID:21112954

Cancherini, D.V., Queliconi, B.B., and Kowaltowski, A.J. 2007. Pharmacological and physiological stimuli do not promote $\mathrm{Ca}^{2+}$-sensitive $\mathrm{K}^{+}$channel activity in isolated heart mitochondria. Cardiovasc. Res. 73: 720-728. PMID:17208207

Cubbon, R.M., Wheatcroft, S.B., Grant, P.J., Gale, C.P., Barth, J.H., Sapsford, R.J., et al. 2007. Temporal trends in mortality of patients with diabetes mellitus suffering acute myocardial infarction: a comparison of over 3000 patients between 1995 and 2003. Eur. Heart J. 28: 540545. PMID:17289742

Das, S., Engelman, R.M., Maulik, N., and Das, D.K. 2006. Angiotensin preconditioning of the heart: evidence for redox signaling. Cell Biochem. Biophys. 44: 103-110. PMID:16456238

Dasgupta, C., and Zhang, L. 2011. Angiotensin II receptors and drug discovery in cardiovascular disease. Drug Discov. Today 16: 22-34. PMID:21147255

Esposito, M., Shah, N.N., Korabathina, R., Pan, C., Paruchuri, V., Finley, J., et al. 2014. Quantitative assessment of myocardial perfusion using time-density curve analysis after elective percutaneous coronary intervention. J. Invasive Cardiol. 26: 60-63. PMID:24486662

Evanson, K.W., Bannister, J.P., Leo, M.D., and Jaggar, J.H. 2014. LRRC26 is a functional BK channel auxiliary gamma subunit in arterial smooth muscle cells. Circ. Res. 115: 423-431. PMID:24906643

Feletou, M. 2009. Calcium-activated potassium channels and endothelial dysfunction: therapeutic options? British J. Pharmacol. 156, 545-562. PMID:19187341

Flynn, J.D., and Akers, W.S. 2003. Effects of the angiotensin II subtype 1 receptor antagonist losartan on functional recovery of isolated rat hearts undergoing global myocardial ischemiareperfusion. Pharmacotherapy 23: 1401-1410. PMID:16420386 
Gao, F., Yue, T.L., Shi, D.W., Christopher, T.A., Lopez, B.L., Ohlstein, E.H., et al. 2002. p38 MAPK inhibition reduces myocardial reperfusion injury via inhibition of endothelial adhesion molecule expression and blockade of PMN accumulation. Cardiovasc. Res. 53: 414-422. PMID:11827692

Gelpi, R.J., Morales, C., Cohen, M.V., and Downey, J.M. 2002. Xanthine oxidase contributes to preconditioning's preservation of left ventricular developed pressure in isolated rat heart: developed pressure may not be an appropriate end-point for studies of preconditioning. Basic Res. Cardiol. 97: 40-46. PMID:11998976

Giacco, F., and Brownlee, M. 2010. Oxidative stress and diabetic complications. Circ. Res. 107: 1058-1070. PMID:21030723

Han, J., Park, S.J., Thu, V.T., Lee, S.R., Long le, T., Kim, H.K., et al. 2013. Effects of the novel angiotensin II receptor type I antagonist, fimasartan on myocardial ischemia/reperfusion injury. Int. J. Cardiol. 168: 2851-2859. PMID:23642815

Hausenloy, D.J., and Yellon, D.M. 2013. Myocardial ischemia-reperfusion injury: a neglected therapeutic target. J. Clin. Invest. 123: 92-100. PMID:23281415

Heinen, A., Strothoff, M., Schmidt, A., Stracke, N., Behmenburg, F., Bauer, I., et al. 2014. Pharmacological options to protect the aged heart from ischemia and reperfusion injury by targeting the PKA-BK $\mathrm{Ca}_{\mathrm{C}}$ signaling pathway. Exp. Gerontol. 56: 99-105. PMID:24727217

Higuchi, T., Fukushima, K., Xia, J., Mathews, W.B., Lautamaki, R., Bravo, P.E., et al. 2010. Radionuclide imaging of angiotensin II type 1 receptor upregulation after myocardial ischemiareperfusion injury. J. Nucl. Med. 51: 1956-1961. PMID:21078800

Hoffmann, R., Haager, P., Lepper, W., Franke, A., and Hanrath, P. 2003. Relation of coronary flow pattern to myocardial blush grade in patients with first acute myocardial infarction. Heart 89: 1147-1151. PMID:12975402

Jaggar, J.H., Wellman, G.C., Heppner, T.J., Porter, V.A., Perez, G.J., Gollasch, M., et al. 1998. $\mathrm{Ca}^{2+}$ channels, ryanodine receptors and $\mathrm{Ca}^{2+}$-activated $\mathrm{K}^{+}$channels: a functional unit for regulating arterial tone. Acta Physiol. Scand. 164: 577-587. PMID:9887980

Kimura, S., Zhang, G.X., Nishiyamam, A., Shokoji, T., Yao, L., Fan, Y.Y., et al. 2005. Role of $\mathrm{NAD}(\mathrm{P}) \mathrm{H}$ oxidase- and mitochondria-derived reactive oxygen species in cardioprotection of ischemic reperfusion injury by angiotensin II. Hypertension 45: 860-866. PMID:15824196

Krajewska, W.M., and Maslowska, I. 2004. Caveolins: structure and function in signal transduction. Cell Mol. Biol Lett. 9: 195-220. PMID:15213803

Kurisu, S., Inoue, I., Kawagoe, T., Ishihara, M., Shimatani, Y., Nishioka, K., et al. 2003. Diabetes mellitus is associated with insufficient microvascular reperfusion following 
revascularization for anterior acute myocardial infarction. Intern. Med. 42: 554-559. PMID:12879945

Lu, T., Chai, Q., Yu, L., d'Uscio, L.V., Katusic, Z.S., He, T., et al. 2012. Reactive oxygen species signaling facilitates FOXO-3a/FBXO-dependent vascular BK channel betal subunit degradation in diabetic mice. Diabetes 61: 1860-1868. PMID: 22586590

Lu, T., Zhang, D.M., Wang, X.L., He, T., Wang, R.X., Chai, Q., et al. 2010. Regulation of coronary arterial BK channels by caveolae-mediated angiotensin II signaling in diabetes mellitus. Circ. Res. 106: 1164-1173. PMID:20167931

Nelson, M.T., Cheng, H., Rubart, M., Santana, L.F., Bonev, A.D., Knot, H.J., et al. 1995. Relaxation of arterial smooth muscle by calcium sparks. Science 270: 633-637. PMID:7570021

Norhammar, A., Lindback, J., Ryden, L., Wallentin, L., and Stenestrand, U. 2007. Improved but still high short- and long-term mortality rates after myocardial infarction in patients with diabetes mellitus: a time-trend report from the Swedish Register of Information and Knowledge about Swedish Heart Intensive Care Admission. Heart 93: 1577-1583. PMID:17237125

Pallone, T.L. 1994. Vasoconstriction of outer medullary vasa recta by angiotensin II is modulated by prostaglandin E2. The Am. J. Physiol. 266: F850-857. PMID:8023965

Park, Y., Prisby, R.D., Behnke, B.J., Dominguez, J.M., II, Lesniewski, L.A., Donato, A.J., et al. 2012. Effects of aging, TNF-alpha, and exercise training on angiotensin II-induced vasoconstriction of rat skeletal muscle arterioles. J. Appl. Physiol. 113: 1091-1100. PMID:22923503

Patzak, A., Bontscho, J., Lai, E., Kupsch, E., Skalweit, A., Richter, C.M., et al. 2005. Angiotensin II sensitivity of afferent glomerular arterioles in endothelin-1 transgenic mice. Nephrol. Dial. Transplant. 20: 2681-2689. PMID: 16188896

Riddle, M.A., Hughes, J.M., and Walker, B.R. 2011. Role of caveolin-1 in endothelial BK $\mathrm{Ca}$ channel regulation of vasoreactivity. Am. J. Physiol. Cell Physiol. 301: C1404-1414. PMID:21900688

Sakamoto, K., Ohya, S., Muraki, K., and Imaizumi, Y. 2008. A novel opener of largeconductance $\mathrm{Ca}^{2+}$-activated $\mathrm{K}^{+}(\mathrm{BK})$ channel reduces ischemic injury in rat cardiac myocytes by activating mitochondrial $\mathrm{K}_{\mathrm{Ca}}$ channel. J. Pharmacol. Sci. 108: 135-139. PMID:18757135

Schneider, C.A., Rasband, W.S., and Eliceiri, K.W. 2012. NIH Image to ImageJ: 25 years of image analysis. Nat. Methods 9: 671-675. PMID:22930834

Singh, H., Lu, R., Bopassa, J.C., Meredith, A.L., Stefani, E., and Toro, L. 2013. MitoBK ${ }_{\mathrm{Ca}}$ is encoded by the KCNMA1 gene, and a splicing sequence defines its mitochondrial location. Proc. Natl. Acad. Sci. USA. 110: 10836-10841. PMID:23754429 
Singh, H., Stefani, E., and Toro, L. 2012. Intracellular $\mathrm{BK}_{\mathrm{Ca}}\left(\mathrm{iBK}_{\mathrm{Ca}}\right)$ channels. J. Physiol. 590: 5937-5947. PMID:22930268

Singh, V.P., Baker, K.M., and Kumar, R. 2008. Activation of the intracellular renin-angiotensin system in cardiac fibroblasts by high glucose: role in extracellular matrix production. Am. J. Physiol. 294: H1675-1684. PMID:18296558

Snell-Bergeon, J.K., and Wadwa, R.P. 2012. Hypoglycemia, diabetes, and cardiovascular disease. Diabetes Technol. Ther. 14 Suppl 1: S51-58. PMID:22650225

Suzuki, M., Sasaki, N., Miki, T., Sakamoto, N., Ohmoto-Sekine, Y., Tamagawa, M., et al. 2002. Role of sarcolemmal $\mathrm{K}_{\mathrm{ATP}}$ channels in cardioprotection against ischemia/reperfusion injury in mice. J. Clin. Invest. 109: 509-516. PMID:11854323

Suzuki, Y., Yamamura, H., Ohya, S., and Imaizumi, Y. 2013. Caveolin-1 Facilitates the Direct Coupling between large conductance $\mathrm{Ca}^{2+}$-activated $\mathrm{K}^{+}\left(\mathrm{BK}_{\mathrm{Ca}}\right)$ and $\mathrm{Cav1.2} \mathrm{Ca}^{2+}$ channels and their clustering to regulate membrane excitability in vascular myocytes. J. Biol. Chem. 288: 36750-36761. PMID:24202214

Tanaka, Y., Meera, P., Song, M., Knaus, H.G., and Toro, L. 1997. Molecular constituents of maxi $\mathrm{K}_{\mathrm{Ca}}$ channels in human coronary smooth muscle: predominant alpha + beta subunit complexes. J. Physiol. 502 ( Pt 3): 545-557. PMID:9278907

Testai, L., Martelli, A., Marino, A., D'Antongiovanni, V., Ciregia, F., Giusti, L., et al. 2013. The activation of mitochondrial BK potassium channels contributes to the protective effects of naringenin against myocardial ischemia/reperfusion injury. Biochem. Pharmacol. 85: 1634-1643. PMID:23567997

Touyz, R.M., and Schiffrin, E.L. 2000. Signal transduction mechanisms mediating the physiological and pathophysiological actions of angiotensin II in vascular smooth muscle cells. Pharmacol. Rev. 52: 639-672. PMID:11121512

Ushio-Fukai, M., and Alexander, R.W. 2006. Caveolin-dependent angiotensin II type 1 receptor signaling in vascular smooth muscle. Hypertension 48: 797-803. PMID:17015782

Van Linthout, S., Spillmann, F., Riad, A., Trimpert, C., Lievens, J., Meloni, M., et al. 2008. Human apolipoprotein A-I gene transfer reduces the development of experimental diabetic cardiomyopathy. Circulation 117: 1563-1573. PMID:18332268

Wackers, F.J. 2005. Diabetes and coronary artery disease: the role of stress myocardial perfusion imaging. Cleve. Clin. J. Med. 72: 21-25, 29-33. PMID:15691055 
Wang, R.X., Shi, H.F., Chai, Q., Wu, Y., Sun, W., Ji, Y., et al. 2012. Molecular mechanisms of diabetic coronary dysfunction due to large conductance $\mathrm{Ca}^{2+}$-activated $\mathrm{K}^{+}$channel impairment. Chin. Med. J. (Engl.) 125: 2548-2555. PMID:22882938

Wang, X.L., Ye, D., Peterson, T.E., Cao, S., Shah, V.H., Katusic, Z.S., et al. 2005. Caveolae targeting and regulation of large conductance $\mathrm{Ca}^{2+}$-activated $\mathrm{K}^{+}$channels in vascular endothelial cells. J. Biol. Chem. 280: 11656-11664. PMID:15665381

Wojtovich, A.P., Nadtochiy, S.M., Urciuoli, W.R., Smith, C.O., Grunnet, M., Nehrke, K., et al. 2013. A non-cardiomyocyte autonomous mechanism of cardioprotection involving the SLO1 BK channel. PeerJ 1, E48. PMID:23638385

Yellon, D.M., and Hausenloy, D.J. 2007. Myocardial reperfusion injury. New Eng. J. Med. 357: 1121-1135. PMID:17855673

Yeung, C.Y., Lam, K.S., Li, S.W., Lam, K.F., Tse, H.F., and Siu, C.W. 2012. Sudden cardiac death after myocardial infarction in type 2 diabetic patients with no residual myocardial ischemia. Diab. Care 35: 2564-2569. PMID:22875229

Yi, F., Wang, H., Chai, Q., Wang, X., Shen, W.K., Willis, M.S., et al. 2014. Regulation of large conductance $\mathrm{Ca}^{2+}$-activated $\mathrm{K}^{+}(\mathrm{BK})$ channel betal subunit expression by muscle RING finger protein 1 in diabetic vessels. J. Biol. Chem. 289: 10853-10864. PMID:24570002

Zhang, D.M., He, T., Katusic, Z.S., Lee, H-C., and Lu, T. 2010. Muscle-specific F-box only proteins facilitate BK channel beta-1 subunit downregulation in vascular smooth muscle cells of diabetes mellitus. Circ. Res. 107: 1454-1459. PMID:20966391

Zhang, Z., Li, M., Lu, R., Alioua, A., Stefani, E., and Toro, L. 2014. The angiotensin II type 1 receptor (AT1R) closely interacts with large conductance voltage- and $\mathrm{Ca}^{2+}$-activated $\mathrm{K}^{+}(\mathrm{BK})$ channels and inhibits their activity independent of G-protein activation. J. Biol. Chem. 289: 25678-25689. PMID:25070892 
Table 1. Left ventricular developed pressure (LVDP, mm Hg) of Langendorff-perfused mouse hearts before after ischemia/reperfusion procedure

\begin{tabular}{|c|c|c|c|c|c|c|c|c|c|c|c|c|c|}
\hline $\begin{array}{l}\text { Mice } \\
\text { Treatment }\end{array}$ & WT, Ctrl & $\begin{array}{l}\text { WT, Ang } \\
\text { II }\end{array}$ & $\begin{array}{c}\text { WT, } \\
\text { IBTX }\end{array}$ & $\begin{array}{l}\text { WT, Ang } \\
\text { II, }\end{array}$ & $\begin{array}{l}\text { WT, Ang } \\
\text { II, }\end{array}$ & $\begin{array}{l}\text { WT, } \\
\text { IBTX, }\end{array}$ & WT, STZ & $\begin{array}{l}\text { WT, } \\
\text { STZ, }\end{array}$ & $\begin{array}{l}\text { Cav-1 }^{-1-} \text {, } \\
\text { Ctrl }\end{array}$ & $\begin{array}{l}\text { Cav-1 }^{-1-} \text {, } \\
\text { Ang II }\end{array}$ & $\begin{array}{l}\text { Cav-1 }^{-1-}, \\
\text { IBTX }\end{array}$ & $\begin{array}{l}\text { Cav-1 }^{-1-}, \\
\text { STZ }\end{array}$ & $\begin{array}{l}\text { Cav-1 }^{-/-} \\
\text {STZ, }\end{array}$ \\
\hline & & & & NS1619 & Losartan & NS1619 & & NS1619 & & & & & NS1619 \\
\hline Before I/R & $86.2 \pm 7.3$ & $91.3 \pm 8.1$ & $86.2 \pm 3.2$ & $90.1 \pm 5.6$ & $81.9 \pm 7.5$ & $83.6 \pm 5.6$ & $82.6 \pm 5.3$ & $90.5 \pm 4.2$ & $83.2 \pm 4.9$ & $72.2 \pm 8.7$ & $76.4 \pm 5.0$ & $78.8 \pm 3.4$ & $86.6 \pm 4.0$ \\
\hline After I/R & $53.4 \pm 4.1^{*}$ & $34.1 \pm 2.6^{*+}$ & $34.2 \pm 3.9^{*+}$ & $48.1 \pm 4.7^{*}$ & $47.4 \pm 7.5^{*}$ & $52.9 \pm 3.0^{*}$ & $30.1 \pm 5.3^{*}+$ & $52.9 \pm 3.1^{*}$ & $55.2 \pm 4.1^{*}$ & $49.2 \pm 5.3 *$ & $38.7 \pm 5.9^{*} \ddagger$ & $48.1 \pm 4.2 *$ & $49.1 \pm 4.3^{*}$ \\
\hline $\mathbf{n}$ & 8 & 7 & 7 & 7 & 8 & 7 & 9 & 8 & 7 & 6 & 6 & 9 & 7 \\
\hline
\end{tabular}

LVDP was significantly decreased in each group after ischemia reperfusion (I/R) procedure. NS1619, losartan and caveolin-1 knockout $\left(\mathrm{Cav}_{-1}^{-/}\right)$counteract the exacerbated effects of diabetes, Ang II and IBTX on LVDP after I/R. Data are presented as mean \pm S.E.M. *: $\mathrm{p}<0.05$ vs before $\mathrm{I} / \mathrm{R} ; \mathrm{\dagger}: \mathrm{p}<0.05$ vs wt controls after $\mathrm{I} / \mathrm{R} ; \ddagger$ : $\mathrm{p}<0.05$ vs $\mathrm{Cav}-1^{-/-}$control mice after I/R. 


\section{Figure Captions}

Figure 1. In vivo myocardial $\mathbf{I} / \mathrm{R}$ injury studies in wt and $\mathrm{Cav}^{-1 /-}$ mice. (A) Myocardial infarction of mice was induced by a 40-min occlusion of the left anterior descending (LAD) coronary artery followed by a 60 -min period of blood reflow. Body surface ECG and femoral artery blood pressure were recorded in diabetic wt mice throughout I/R procedure. Selected ECG recordings before and after $40 \mathrm{~min}$ of LAD occlusion are expanded to show $\mathrm{S}-\mathrm{T}$ segment elevations (arrows) and pathological Q waves (asterisks) during blood reflow. (B) Representative photographs showing the healthy tissue and the infarct areas in myocardial slices. Diabetic wt mice (STZ) had a significant increase in I/R-induced myocardial infarct size, compared to that of non-diabetic wt controls. However, diabetes has no effect on infarct size in $\mathrm{Cav}-1^{-/}$mice. Group data with statistical analyses are shown in the bar graphs. $*: \mathrm{p}<0.05$ vs wt controls; $\mathrm{t}: \mathrm{p}<0.05$ vs wt STZ.

Figure 2. Ex vivo myocardial $\mathbf{I} / \mathrm{R}$ injury studies in wt mice. Representative photographs of myocardial slices from wt control and diabetic mice under different experimental conditions as indicated. Isolated hearts were pretreated with chemicals for $30 \mathrm{~min}$, followed by $40 \mathrm{~min}$ of global ischemia and then 60 min of reperfusion with the same chemicals. Treatment with Ang II $(2 \mu \mathrm{M})$ and IBTX $(0.2 \mu \mathrm{M})$ produced a significantly larger infarct size, with values similar to that in diabetes (STZ). The effects of Ang II on I/R-induced infarct size were reduced by NS1619 $(10 \mu \mathrm{M})$ and Losartan $(10 \mu \mathrm{M})$. However, the effect of IBTX was not altered by NS1619. Group data with statistical analysis are shown in the bar graphs. *: $p<0.05$ vs controls; t: $\mathrm{p}<0.05$ vs STZ; $: \mathrm{p}<0.05$ vs Ang II+NS1619.

Figure 3. Ex vivo myocardial $\mathbf{I} / \mathrm{R}$ injury studies in $\mathbf{C a v - 1 ^ { - / - }}$ mice. Representative photographs of myocardial slices from Cav-1//- mice under different experimental conditions as indicated. 
Myocardial infarct size induced by I/R injury was increased by Ang II $(2 \mu \mathrm{M})$ and with diabetes, but the lesions were about $40 \%$ smaller than those in wt mice. Infarct size in $\mathrm{Cav}-1^{-/}$mice doubled after pretreatment with IBTX, comparable to those with Ang II and with diabetes (STZ), suggesting the BK channel activity is important in determining infarct size and the absence of Cav-1 is protective against I/R-induced injury. Group data with statistical analysis are shown in the bar graphs. $*: \mathrm{p}<0.05$ vs controls; $+: \mathrm{p}<0.05$ vs Ang II and STZ; $¥: \mathrm{p}<0.05$ vs STZ.

\section{Figure 4. Colocalization of BK- $\alpha$ and AT1R, but not BK- $\beta 1$, in the caveolae of vascular}

SMCs. (A) Western blots showing BK- $\alpha$ and AT1R proteins were present in the low-buoyant density, caveolae-rich membrane fractions (fraction No. 2 to 4 ) and in cell lysates of mouse aortas. There were very little protein expression of BK- $\beta 1$ in the caveolae-rich membrane fractions, compared to that of cell lysate and the heavy density fractions (No. 7 to 8). (B) Freshly isolated coronary SMCs of mice were incubated with anti-Cav-1, anti-BK- $\alpha$ and anti-AT1R antibodies, and the primary antibodies were detected by fluorescein isothiocyanate-conjugated goat anti-mouse secondary antibody or with Texas Red-conjugated goat-anti-rabbit secondary antibody. Fluorescence images show the overlap of the signals between BK- $\alpha$ (red) and Cav-1 (green) (upper panel), as well as between AT1R (red) and BK- $\alpha$ (green) (lower panel). Pixel-bypixel colocalization was estimated using a linear equation with the slope (Pearson correlation coefficient, $\gamma$ ) of 0.77 and 0.82 respectively. (C) Western blotting analysis shows the pulldowns of anti-Cav-1 antibody from two pairs of control and STZ-induced diabetic mouse aorta homogenates blotted against anti-BK- $\alpha$ and anti-AT1R antibodies. BK- $\alpha$ and AT1R proteins were markedly enriched in the pulldowns of diabetic mouse aortas. Group data with statistical significance are illustrated in the bar graphs. 
Figure 5. Effects of Ang II on HEK293 cells stably expressing hSlo. (A) hSlo currents were continuously elicited at $+100 \mathrm{mV}$ from a holding potential of $-60 \mathrm{mV}$ at 10 -s intervals in HEK293 cells stably expression hSlo gene (hSlo-HEK293 cell line), $48 \mathrm{~h}$ after transient transfection with Cav-1 and AT1R wt cDNAs. The time course (left panel) and representative tracings (right panel) of hSlo currents in response to Ang II $(2 \mu \mathrm{M})$, Losartan $(10 \mu \mathrm{M})$ and IBTX $(0.1 \mu \mathrm{M})$ are shown. Ang II inhibited the hSlo currents by $50 \%$ and the effect of Ang II was blocked by Losartan. (B) The I-V curves of hSlo currents recorded from hSlo-HEK293 cell line $48 \mathrm{~h}$ after co-expression with AT1R wt cDNA at baseline and exposure to $2 \mu \mathrm{M}$ Ang II (left) or $2 \mu \mathrm{M}$ Ang II $+10 \mu \mathrm{M}$ Losartan (right) show that the inhibitory effects of Ang II on hSlo currents were blocked by Losartan. *: $<0.05$ ( $\mathrm{n}=5$ for both groups).

Figure 6. Mutation in the Cav-1 binding motif in $\mathrm{AT}_{1} \mathrm{R}$ abolished the Ang II effect on hSlo currents. (A) Time course of the effects of Ang II $(2 \mu \mathrm{M})$, IBTX $(0.1 \mu \mathrm{M})$ and wash out of chemicals on hSlo currents stably expressed in HEK293 cells, 48 h after co-transfection with Cav-1 wt and AT1R F309A mutant cDNAs. The Ang II did not inhibit hSlo channels which were inhibited by IBTX, indicating that hSlo channels were present and active but the $\mathrm{AT}_{1} \mathrm{R}$ mutant was unable to mediate the inhibitory effects of Ang II on BK channels. (B) Whole-cell hSlo currents recorded from hSlo-HEK293 cells co-expressing Cav-1 and AT1R F309A (left column) and their I-V relationships (right column) elicited from $-40 \mathrm{mV}$ to $+150 \mathrm{mV}$ at a holding potential of $-60 \mathrm{mV}$ before and after exposure to Ang II. Ang II failed to inhibit the hSlo channels. 


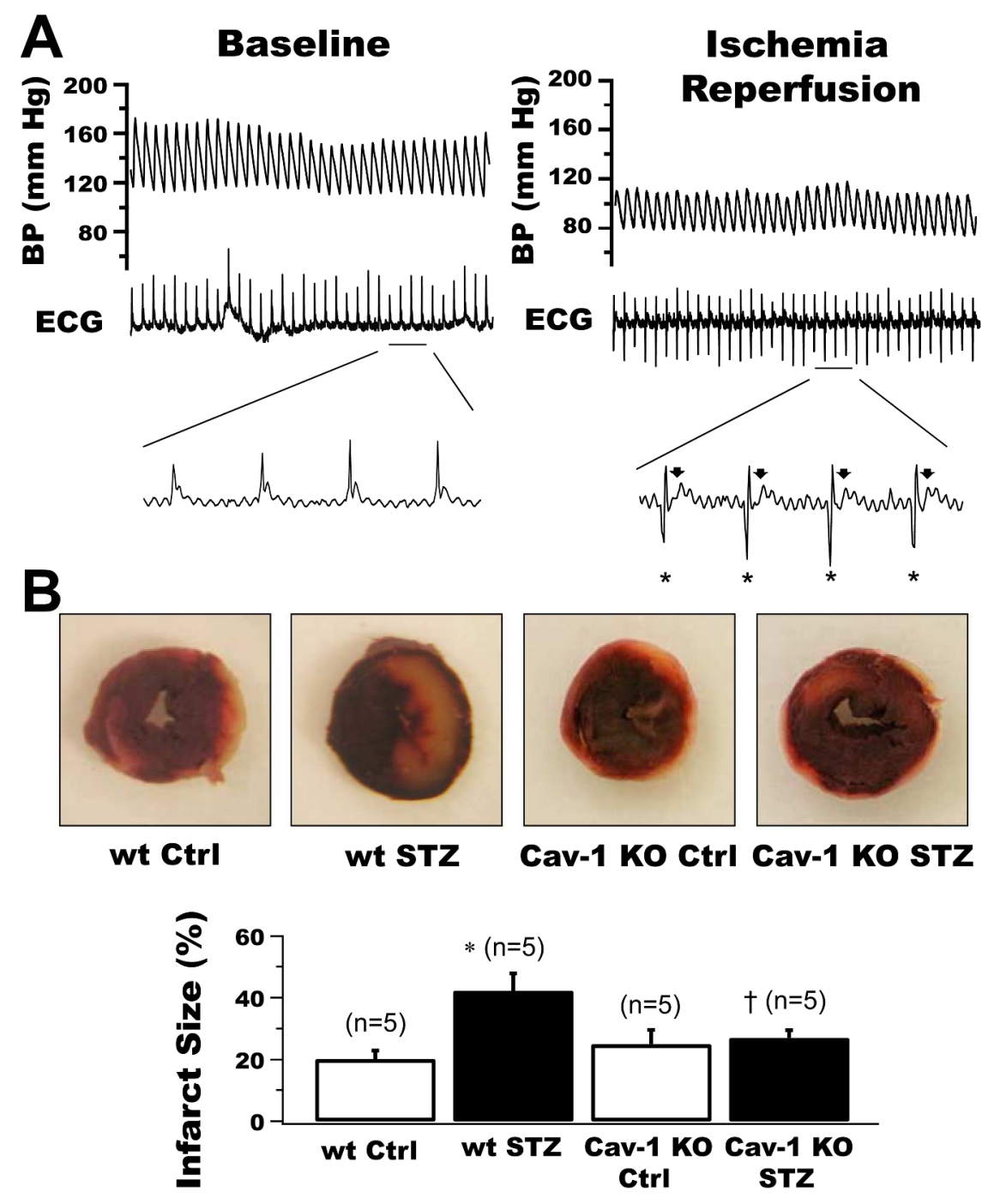




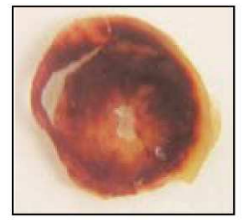

wt (Ctrl)

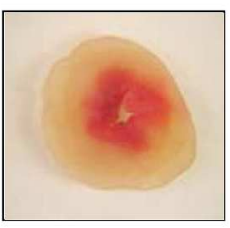

wt (IBTX)

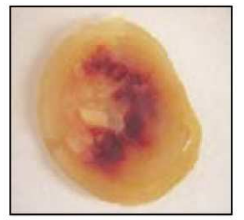

wt (Ang II)

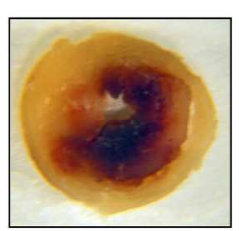

wt (IBTX, NS1619)

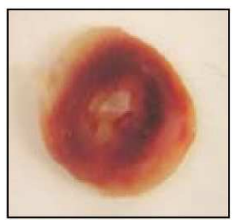

wt (Ang II, Losartan)

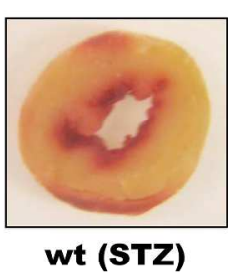

wt (STZ)

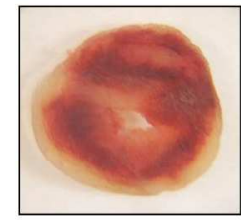

wt (Ang II, NS1619)

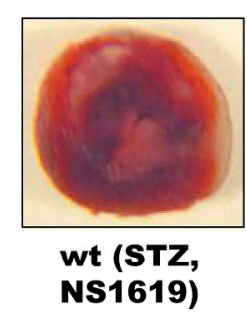

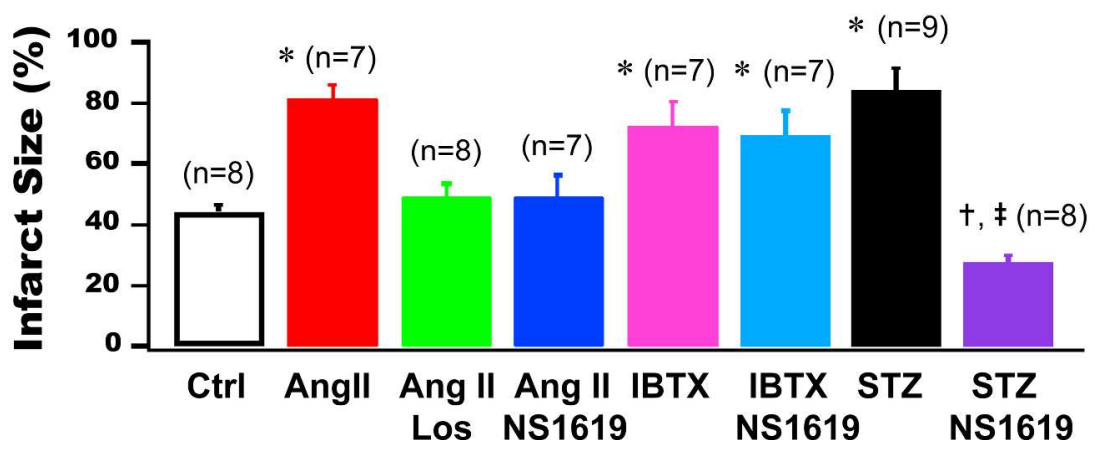

$254 \times 330 \mathrm{~mm}(300 \times 300$ DPI $)$ 


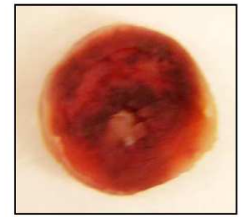

Cav-1 Ko

(Ctrl)

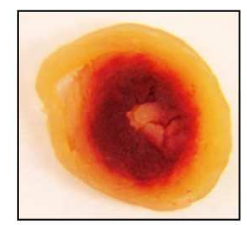

Cav-1 Ko (STZ)

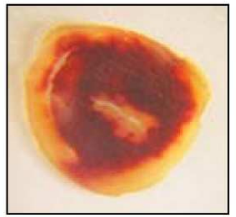

Cav-1 KO

(Ang II)

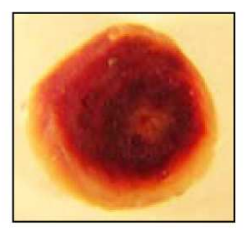

Cav-1 Ko

(STZ, NS1619)
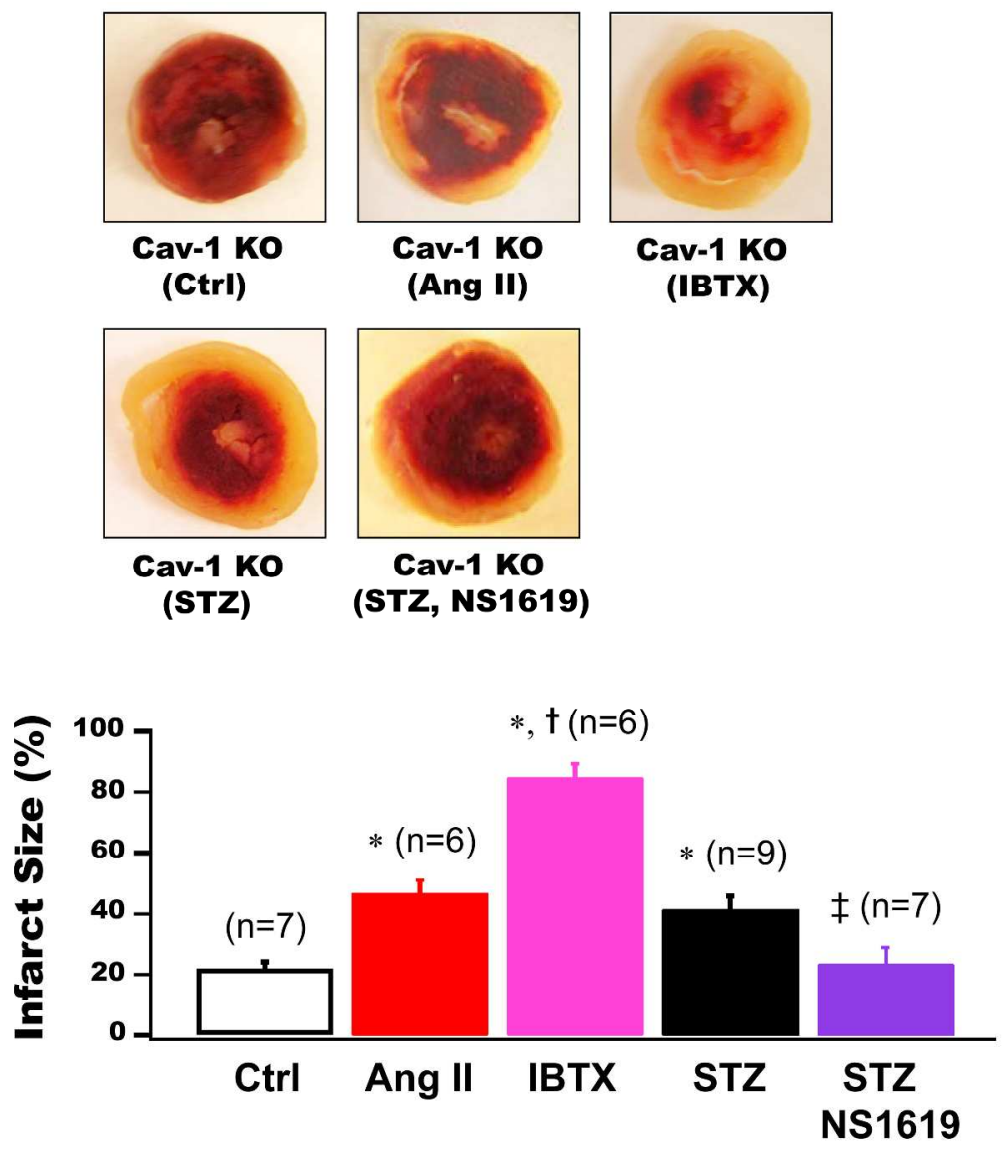

$254 \times 338 \mathrm{~mm}(300 \times 300$ DPI $)$ 
A



B
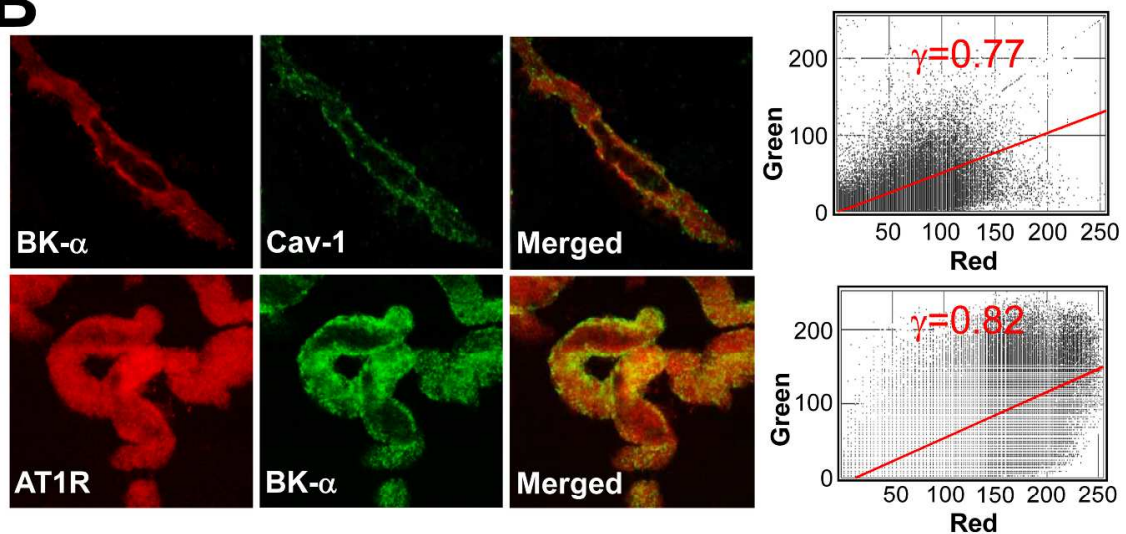

C IP: anti-Cav-1 antibody

BK- $\alpha \quad$ AT1R
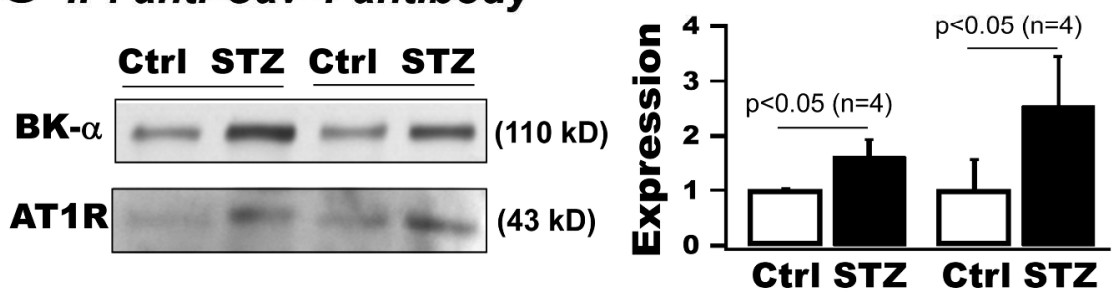

$256 \times 322 \mathrm{~mm}(300 \times 300$ DPI $)$ 

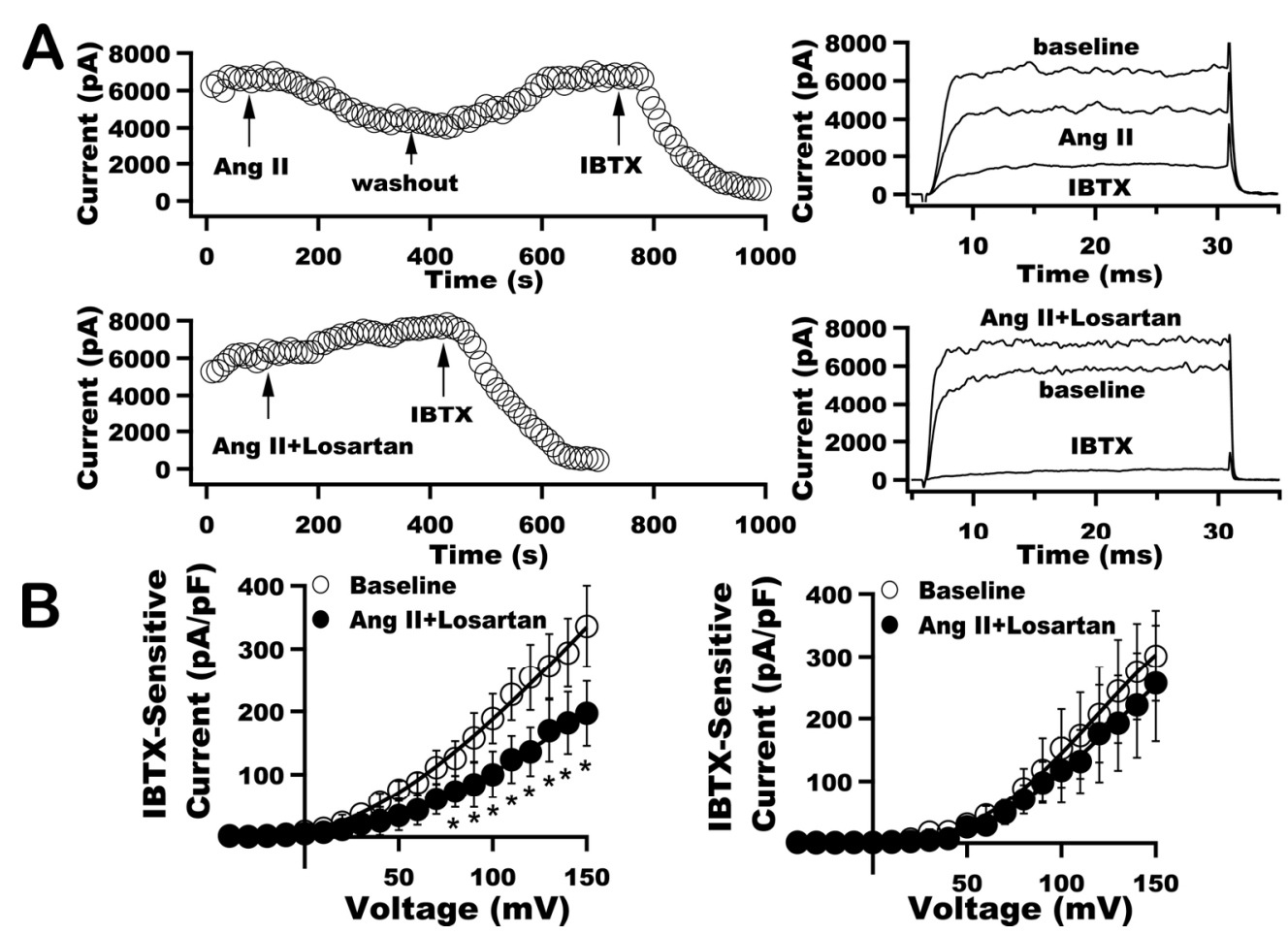

$163 \times 116 \mathrm{~mm}(300 \times 300 \mathrm{DPI})$ 

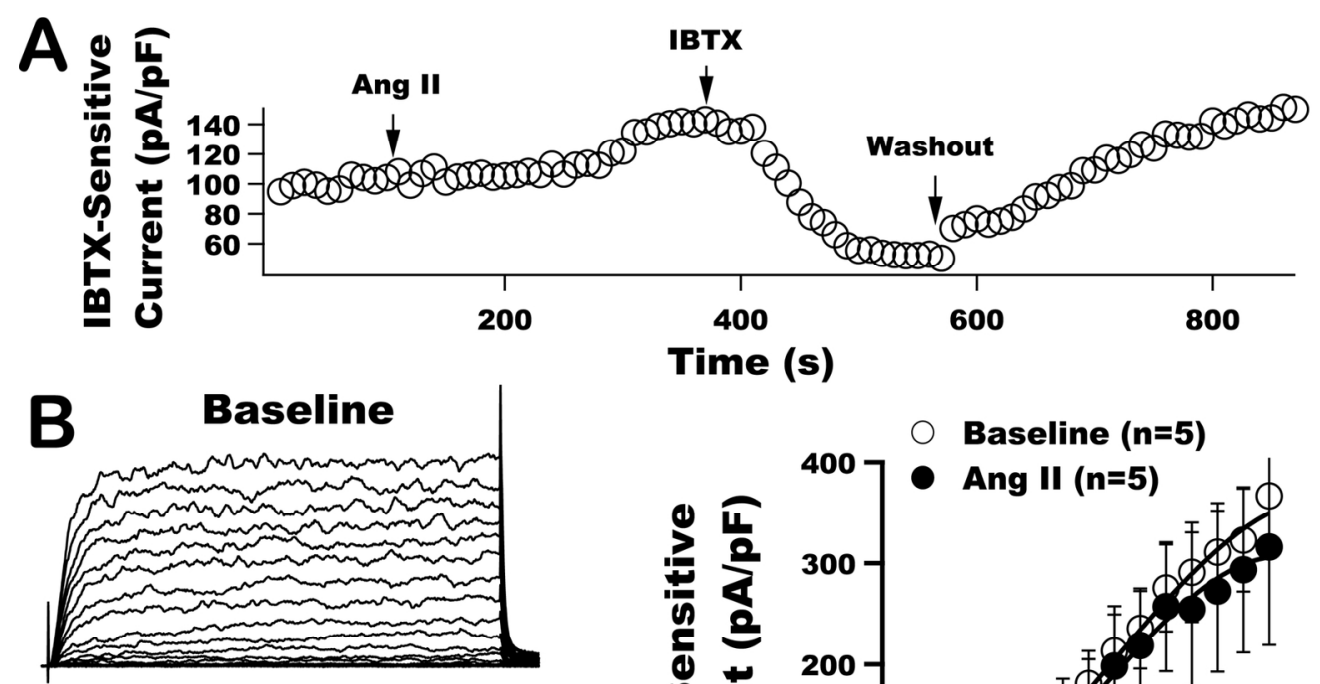

Time (s)

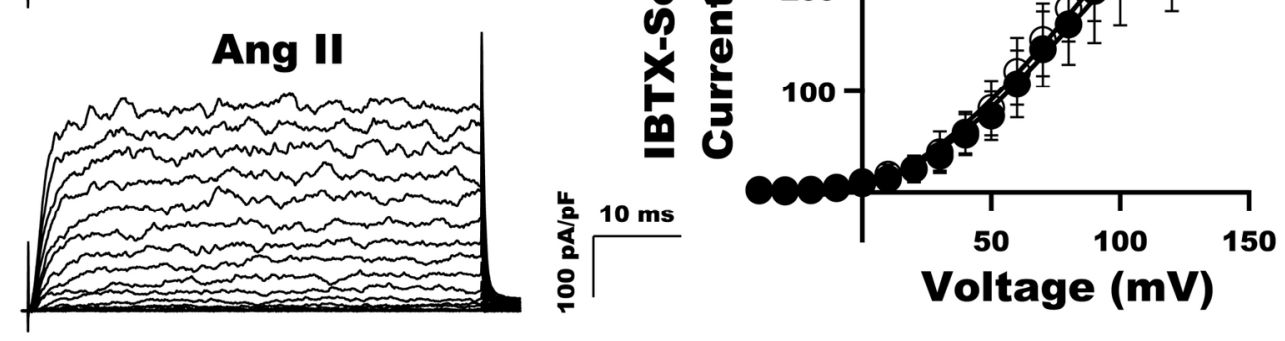

$152 \times 116 \mathrm{~mm}(300 \times 300$ DPI $)$ 